\title{
Uso da tecnologia da informação na gestão da cadeia de suprimentos em São Luís do Maranhão e oportunidades para o desenvolvimento de fornecedores locais
}

Use of information technology in supply chain management in São Luís do

Maranhão and opportunities to the development of local suppliers

Utilisation des technologies de d'information sur la gestion de la chaine

d'approvisionnement à São Luís do Maranhão et opportunites pour le developpement des fournisseurs locaux

Uso de la tecnología de la información sobre la gestión de la cadena de suministro en São Luís do Maranhão y oportunidades para el desarrollo de proveedores locales

\author{
Káty Maria Nogueira Morais* \\ Elaine Tavares**
}

Recebido em 8/9/2010; revisado e aprovado em 18/12/2010; aceito em 4/2/2011

\begin{abstract}
Resumo: A pesquisa descrita neste artigo teve como objetivo analisar como a tecnologia da informação (TI) vem sendo utilizada para auxiliar a gestão da cadeia de suprimentos (GCS) na cidade de São Luís do Maranhão. Os resultados retratam quais tecnologias são mais empregadas e quais são pouco utilizadas, assim como benefícios e barreiras para esta adoção. Revela-se um cenário de oportunidades para o uso efetivo da TI, que poderá contribuir para o desenvolvimento local, por meio da mudança de realidade de seus fornecedores.

Palavras-chave: Tecnologia da informação. Gestão da cadeia de suprimentos. Maranhão.
\end{abstract}

Abstract: The research described in this article aims to examine how information technology (IT) has been applied in supply chain management (SCM) in the city of São Luís do Maranhão. Results indicate which technologies are most used and which are not widely applied, as well as benefits and barriers to this adoption. It reveals a scenario of opportunities for the effective use of IT, which could contribute to local development, through the changing reality of its suppliers.

Key words: Information technology. Supply chain management. Maranhão.

Résumé: La recherche décrite dans cet article vise à examiner comment les technologies de l'information (TI) a été utilisé sur la gestion de la chaîne d'approvisionnement à São Luís do Maranhão. Les résultats indiquent que technologies sont les plus utilisés et qui ne sont pas largement utilisé, ainsi que les avantages et les obstacles à cette adoption. Il se révèle un scénario de possibilités pour l'utilisation efficace des TI, ce qui pourrait contribuer au développement local, à travers la réalité changeante de ses fournisseurs.

Mots-clés : Technologies de l'information. Gestion de la chaîne d'approvisionnement. Maranhão.

Resumen: La investigación descrita en este artículo tiene por objeto analizar cómo la tecnología de la información (TI) se ha utilizado em la gestión de la cadena de suministro en São Luís do Maranhão. Los resultados indican las tecnologías más utilizadas y que casi no se usan, así como los beneficios y los obstáculos para su adopción. Se revela un escenario de oportunidades para el uso eficaz de las TI, que pueden contribuir al desarrollo local, a través de la cambiante realidad de sus proveedores.

Palabras clave: Tecnología de la información. Gestión de la cadena de suministro. Maranhão.

Introdução

A tecnologia da informação (TI) tem exercido grande influência sobre a vida das pessoas, promovendo significativas mudanças em aspectos, como relações sociais, de trabalho e nos processos organizacionais.

No âmbito das organizações, o impacto da TI demanda especial atenção. Para Motta (2005), “[...] a empresa se tornará cada vez mais fragmentada, localizada, descentralizada, flexibilizada e capaz de múltiplas configurações".
$\mathrm{Na}$ busca de melhor desempenho ou para aquisição de vantagens competitivas, as organizações necessitam ter grande capacidade de adequação às novas exigências do mercado. Em diferentes áreas, isto se torna verdade. Entretanto, quando se pensa em tecnologia da informação, área em que as mudanças acontecem mais velozmente, faz-se necessária uma atenção ainda maior. Isso tendo em vista que ela passa de uma área de suporte ao negócio da empresa para uma área que estabelece a estruturação dos processos internos e operações.

\footnotetext{
* Mestre em Gestão Empresarial pela Escola Brasileira de Administração Pública e de Empresas da Fundação Getulio Vargas (EBAPE/FGV). Professora da Universidade do Estado do Maranhão (UEMA). E-mail: katymaria@hotmail.com. ${ }^{* *}$ Doutora em Administração pela EBAPE/FGV. Professora da EBAPE/FGV. Pós-Doutoranda do Centre d'Etude et de Recherche en Gestion Aix Marseille - Université Aix-Marseille. E-mail: elaine.tavares@fgv.br.
} 
Uma dessas operações é a gestão da cadeia de suprimentos (GCS), que também passou por significativas alterações e hoje sofre expressiva influência de TI. Empresas modernas vêm utilizando-se da ampliação da capacidade logística para a implementação de suas estratégias competitivas. Nesse contexto, a busca pela melhoria dos processos e aumento da eficiência operacional na gestão da cadeia de suprimentos é constante.

Com a estabilização da economia brasileira a partir da segunda metade da década de 1990, as empresas começaram a melhor gerenciar e integrar suas atividades de abastecimento e distribuição. Resulta dessa assertiva a necessidade de as organizações buscarem instrumentos que favoreçam a gestão e integração das atividades, dentre os quais se destacam os sistemas de gestão. A tecnologia voltada para a GCS tornou-se, portanto, relevante para a competitividade das organizações (BARAT, 2007).

A TI passou assim a ser usada como uma ferramenta estratégica para a GCS, tendo o compartilhamento ágil de informações com os fornecedores como um dos aspectos mais importantes no processo de GCS, ao produzir efeitos na redução de custos de transação e de negociação com os fornecedores (COSTA; MAÇADA, 2006; CUNHA; ZWICKER, 2009; MAÇADA; FELDENS; SANTOS, 2007).

Tal fato pode estar consolidado em grandes centros. Contudo, a aplicação de ferramentas de TI na GCS em contextos locais ainda é pouco conhecida. Mediante este cenário, este artigo apresenta uma pesquisa realizada com o objetivo de analisar como a tecnologia da informação vem sendo utilizada para auxiliar a gestão da cadeia de suprimentos na cidade de São Luís do Maranhão.

Parte-se da ideia de que estudos desta natureza podem favorecer o desenvolvimento dos fornecedores locais e, por consequência, colaborar para o desenvolvimento do estado maranhense. O Maranhão é um estado reconhecidamente pobre e com indicadores de desenvolvimento muito inferiores aos demais estados do país. O estado padece de baixos índices socioeconômicos, que o remetem à última posição entre as unidades da Federação brasileira em renda per capita, além de contar com o baixo Índice de Desenvolvimento Humano (IDH) de 0,683, medido em 2008. Em relação ao acesso à internet no Maranhão, convém ressaltar que o percentual de pessoas que utilizaram a rede na população de 10 anos ou mais de idade foi 20,2\%, em 2008 - a penúltima posição, quando comparado aos demais estados do Nordeste (IBGE, 2008). Pelo exposto, sabe-se da importância do desenvolvimento de suas organizações. Fica evidente também a necessidade de expansão da utilização de TI entre os fornecedores locais.

Este artigo apresenta inicialmente o referencial teórico que deu suporte à pesquisa. Tratou-se nesta seção das tecnologias da informação utilizadas na GCS, dos benefícios que elas proporcionam, do compartilhamento de informação na GCS e das barreiras para o uso da TI na GCS. O método utilizado e a análise dos dados são descritos na continuação. Apresenta-se a utilização da TI na GCS no contexto investigado, as razões da não utilização destes recursos, os benefícios apontados por quem usa TI na GCS, o tipo, a frequência e a forma de compartilhamento de informação na GCS, as tecnologias que se pretende implantar em breve e os inibidores do uso da TI na GCS identificados. As considerações finais discutem a incipiência do uso da TI na GCS em São Luís e trazem sugestões de pesquisas futuras.

\section{Referencial teórico}

A tecnologia da informação na gestão da cadeia de suprimentos

A recente evolução da tecnologia da informação teve reflexo na cadeia de suprimentos, área que tinha grande parte de suas atividades gerenciadas através de anotações manuais, implicando alto índice de ineficiência (TURBAN; MCLEAN; WETHERBE, 2004). A TI hoje sustenta operações de empresas, une elos distantes de cadeias de fornecimento e, cada vez mais, liga empresas a clientes (CARR, 2003).

$\mathrm{Na}$ fase inicial da inserção da TI na gestão da cadeia de suprimentos, a busca de um desempenho superior motivou as organizações a implementar alguns softwares, que davam suporte a segmentos isolados da cadeia e tinham como benefícios a redução de custos, agilidade nos processos e diminuição do número de erros. Podem ser citados como 
exemplo os sistemas de gestão de estoque, cronograma de produção e faturamento (TURBAN; MCLEAN; WETHERBE, 2004).

A etapa seguinte teve como demanda principal a necessidade de atender à interdependência existente entre algumas atividades da cadeia de suprimentos, como por exemplo, fazer a interligação da área de programação de produção com a gestão de estoques e o planejamento das compras. O modelo criado foi chamado de planejamento das necessidades de materiais (MRP - Material Resource Planning), que consiste num um método mecânico formal de programação de suprimentos no qual o tempo de compras ou de saída da produção é sincronizado para satisfazer necessidades operacionais período a período, ao equilibrar a requisição de suprimento para as necessidades pela duração do tempo de reabastecimento (BALLOU, 2001). Posteriormente, surgiu o MRP II, cujo modelo é acrescentado com variáveis como recursos de trabalho e planejamento financeiro (TURBAN; MCLEAN; WETHERBE, 2004).

A evolução contínua proporcionou a integração cada vez mais intensa entre os sistemas funcionais. Prova disso são os chamados sistemas integrados de gestão (ERP) que possibilitam às empresas a substituição de sistemas isolados, que vão sendo instalados com o passar dos anos, por um sistema de gestão integrado, que seja capaz de planejar e administrar os recursos de toda a organização (TURBAN; MCLEAN; WETHERBE, 2004).

No contexto de crescente desenvolvimento, surgem as tecnologias que apóiam a
SCM, como código de barras, desenho assistido por computador (CAD), intercâmbio eletrônico de dados (EDI), intranet/extranet, rastreamento de frotas, sistema de execução de manufatura (MES), sistema de gerenciamento de transporte (TMS), sistema de gestão de armazém (WMS), sistema de gestão de relacionamento com clientes (CRM), sistema de identificação por radio frequência (RFID) e sistema de planejamento da cadeia de suprimentos (SCP) (COSTA, 2005; FELDENS, 2005).

Em resumo, os sistemas de informação da cadeia de suprimentos iniciam atividades e rastreiam informações sobre processos, facilitam o compartilhamento de informações, tanto dentro da empresa como entre parceiros da cadeia de suprimentos, e auxiliam a tomada de decisão gerencial (BOWERSOX; CLOSS; COOPER, 2007).

São os sistemas de informação da cadeia de suprimentos (SCIS) que formam o laço que une as atividades logísticas a um processo integrado. Um SCIS abrangente inicia, monitora, subsidia a tomada de decisões e descreve as atividades necessárias para realizar operações e planejamento logístico. Para Bowersox, Closs e Cooper (2007, p. 111)

[...] os principais componentes do SCIS são os seguintes: (1) planejamento de recursos empresariais (ERP); (2) sistemas de comunicação; (3) sistemas de execução; e (4) sistemas de planejamento.

Para fins desta pesquisa, foram consideradas algumas das tecnologias que apóiam a gestão na cadeia de suprimentos, detalhadas no quadro 1. 


\begin{tabular}{|c|c|c|}
\hline Tecnologia & Descrição e Benefícios & Fontes \\
\hline Código de barras & $\begin{array}{l}\text { Código legível por computadores em itens, caixas, } \\
\text { contêiners, paletas e até vagões de cargas. } \\
\text { Benefícios: } \\
\text { - Substitui o processo de coleta e troca de infor- } \\
\text { mações em papel, com riscos de erro e retrabalho } \\
\text { constantes. } \\
\text { - Rápida implantação, } \\
\text { - Fácil utilização } \\
\text { - Equipamentos compactos }\end{array}$ & $\begin{array}{l}\text { BOWERSOX; CLOSS; } \\
\text { COOPER, } 2007 \\
\text { FRANCISCHINI, } 2004 \\
\text { GRAEML; GRAEML; } \\
\text { CSILLAG, } 2005\end{array}$ \\
\hline $\begin{array}{l}\text { Desenho assisti- } \\
\text { do por computa- } \\
\text { dor (CAD) }\end{array}$ & $\begin{array}{l}\text { Permite fazer desenhos no computador, que poste- } \\
\text { riormente podem ser armazenados, manipulados e } \\
\text { atualizados eletronicamente. } \\
\text { Benefícios: } \\
\text { - Criação de movimentos no desenho, permitindo } \\
\text { realizar testes antes da produção. } \\
\text { - Redução do tempo para desenvolvimento de } \\
\text { produtos } \\
\text { - Criação de desenhos de melhor qualidade para } \\
\text { facilitar a comunicação com os parceiros } \\
\text { - Maior flexibilidade e respostas mais rápidas nas } \\
\text { modificações de design } \\
\text { - Oferta de dados de entrada para a manufatura } \\
\text { computadorizada }\end{array}$ & $\begin{array}{l}\text { MALHOTRA; HEINE; } \\
\text { GROVER, } 2001 \\
\text { TURBAN; MCLEAN; } \\
\text { WETHERBE, } 2004\end{array}$ \\
\hline $\begin{array}{l}\text { Intercâmbio } \\
\text { eletrônico de } \\
\text { dados (EDI) }\end{array}$ & $\begin{array}{l}\text { Movimentação eletrônica de documentos comer- } \\
\text { ciais padronizados, como pedidos, faturas e confir- } \\
\text { mações, entre parceiros comerciais. } \\
\text { Benefício: } \\
\text { - Possibilidade de integração entre organizações } \\
\text { em aplicações como contas a pagar, controle de } \\
\text { estoque, remessa e planejamento de produção. }\end{array}$ & $\begin{array}{l}\text { GRAEML; GRAEML; } \\
\text { CSILLAG, } 2005 \\
\text { LAUDON; LAUDON, } \\
1999 \\
\text { TURBAN; MCLEAN; } \\
\text { WETHERBE, } 2004\end{array}$ \\
\hline Intranet/Extranet & $\begin{array}{l}\text { Intranet: Rede interna da organização, baseada na } \\
\text { Internet } \\
\text { Benefícios: } \\
\text { - Rede segura } \\
\text { - Fácil e barata de ser desenvolvida } \\
\text { - Redução dos custos de distribuição da infor- } \\
\text { mação } \\
\text { - Facilidade de uso } \\
\text { - Possibilidade de interação } \\
\text { Extranet: extensão do acesso da rede interna a } \\
\text { parceiros de negócios. } \\
\text { Benefícios: } \\
\text { - Os mesmos da Intranet, com ênfase para a } \\
\text { redução de custos no compartilhamento das infor- } \\
\text { mações }\end{array}$ & $\begin{array}{l}\text { GRAEML; GRAEML; } \\
\text { CSILLAG, } 2005 \\
\text { LAUDON; LAUDON, } \\
1999 \\
\text { O'BRIEN, } 2001\end{array}$ \\
\hline $\begin{array}{l}\text { Rastreamento de } \\
\text { frota }\end{array}$ & $\begin{array}{l}\text { Mecanismos tecnológicos de localização e monito- } \\
\text { ramento de cargas em trânsito. } \\
\text { Benefícios: } \\
\text { - Contribuem para a gestão da frota e da carga e } \\
\text { para o controle das horas de serviços dos mo- } \\
\text { toristas }\end{array}$ & $\begin{array}{l}\text { BOWERSOX; CLOSS; } \\
\text { COOPER, } 2007\end{array}$ \\
\hline
\end{tabular}




\begin{tabular}{|c|c|c|}
\hline Tecnologia & Descrição e Benefícios & Fontes \\
\hline $\begin{array}{l}\text { Sistema de ex- } \\
\text { ecução de manu- } \\
\text { fatura (MES) }\end{array}$ & $\begin{array}{l}\text { Monitoram, acompanham e controlam os cinco } \\
\text { componentes essenciais envolvidos no processo } \\
\text { de produção: matéria-prima, equipamento, pes- } \\
\text { soal, instruções e especificações e instalações de } \\
\text { produção. } \\
\text { Benefícios: } \\
\text { - Processo de manufatura flexível e de alta quali- } \\
\text { dade. }\end{array}$ & O'BRIEN, 2001 \\
\hline $\begin{array}{l}\text { Sistema de ger- } \\
\text { enciamento de } \\
\text { transporte (TMS) }\end{array}$ & $\begin{array}{l}\text { Sistema que controla o transporte de cargas. Calcu- } \\
\text { la melhor rota, identifica o modal mais econômico, } \\
\text { faz o rastreamento de carga pela Internet e geren- } \\
\text { cia reclamações. } \\
\text { Benefícios: } \\
\text { - Redução de custos. } \\
\text { - Gestão eficiente dos fretes e coordenação dos } \\
\text { esforços de transporte. }\end{array}$ & $\begin{array}{l}\text { GILMORE; TOMPKINS, } \\
2000\end{array}$ \\
\hline $\begin{array}{l}\text { Sistema de gestão } \\
\text { de armazém } \\
\text { (WMS) }\end{array}$ & $\begin{array}{l}\text { Utilizado para o controle de movimentação de } \\
\text { itens de estoque no depósito, tem como principais } \\
\text { usos a coordenação e separação de pedidos. } \\
\text { Benefício: } \\
\text { - Melhoria do processo de distribuição. }\end{array}$ & $\begin{array}{l}\text { BOWERSOX; CLOSS; } \\
\text { COOPER, } 2007\end{array}$ \\
\hline $\begin{array}{l}\text { Sistema de rela- } \\
\text { cionamento com } \\
\text { cliente (CRM) }\end{array}$ & $\begin{array}{l}\text { O CRM possibilita a interface entre áreas distintas, } \\
\text { como, marketing e logística, abrangendo o con- } \\
\text { ceito de serviço ao cliente por toda a organização. } \\
\text { O seu particular desenvolvimento na gestão da } \\
\text { cadeia de suprimentos contribui para disseminar } \\
\text { a informação relacionada à distribuição física, que } \\
\text { favorece o atendimento ao consumidor. } \\
\text { Benefício: } \\
\text { - Satisfação e fidelidade do cliente }\end{array}$ & $\begin{array}{l}\text { FRANCO JÚNIOR, } 2001 \\
\text { WOUTERS, } 2001\end{array}$ \\
\hline $\begin{array}{l}\text { Sistema de } \\
\text { identificação por } \\
\text { rádio frequência } \\
\text { (RFID) }\end{array}$ & $\begin{array}{l}\text { Um tag com chip pode identificar o fabricante, o } \\
\text { tipo de produto e até mesmo um número de série } \\
\text { para a marca, permitindo que os itens individuais } \\
\text { sejam identificados. Permite que o conjunto de } \\
\text { produtos seja identificado coletivamente. } \\
\text { Benefícios: } \\
\text { - Redução das despesas com armazéns de dis- } \\
\text { tribuição, manuseio no varejo e faltas de estoque. }\end{array}$ & $\begin{array}{l}\text { BOWERSOX; CLOSS; } \\
\text { COOPER, } 2007 \\
\text { GRAEML; GRAEML; } \\
\text { CSILLAG, } 2005 \\
\text { SANTOS; SMITH, } 2008\end{array}$ \\
\hline $\begin{array}{l}\text { Sistema de } \\
\text { planejamento da } \\
\text { cadeia de supri- } \\
\text { mentos (SCP) }\end{array}$ & $\begin{array}{l}\text { Componentes de planejamento e coordenação do } \\
\text { sistema da cadeia de suprimentos, que são úteis } \\
\text { para orientar a alocação de recursos empresariais } \\
\text { e o desempenho de compras até a entrega do } \\
\text { produto. } \\
\text { Benefício: } \\
\text { - Obtenção de dados reais de demanda, tempo e } \\
\text { inventário. }\end{array}$ & $\begin{array}{l}\text { BOWERSOX; CLOSS; } \\
\text { COOPER, } 2007 \\
\text { WANG; WEI, } 2007\end{array}$ \\
\hline $\begin{array}{l}\text { Sistema inte- } \\
\text { grado de gestão } \\
(\mathrm{ERP})\end{array}$ & $\begin{array}{l}\text { Módulos que disponibilizam informações de dif- } \\
\text { erentes áreas, com a pretensão de suportar todas } \\
\text { as necessidades de informação para a tomada de } \\
\text { decisão das empresas. Há situações de interligação } \\
\text { entre diferentes empresas. } \\
\text { Benefícios: } \\
\text { - Integração e eficiência no fluxo de informação na } \\
\text { organização e/ou entre ela e seus parceiros. }\end{array}$ & $\begin{array}{l}\text { CORRÊA; CORRÊA, } 2001 \\
\text { RANGANATHAN; } \\
\text { DHALIWAL; TEO, } 2004\end{array}$ \\
\hline
\end{tabular}

Quadro 1 - Tecnologias da Informação que auxiliam a GCS. 
Benefícios da tecnologia da informação na gestão da cadeia de suprimentos

Para entender os benefícios da tecnologia da informação na gestão da cadeia de suprimentos, busca-se apoio em alguns estudos que se dedicaram a identificá-los e mensurá-los (ALBERTIN; ALBERTIN, 2005; DIAS; PITASSI; JOIA, 2003; FELDENS, 2005).

Dias, Pitassi e Joia (2003, p. 10) destacam que os benefícios da implantação de aplicativos baseados na web para a função logística são: (i) compartilhar informações de venda e de planejamento com os fornecedores de modo a assegurar que o produto adequado estará na hora correta à disposição do cliente certo; (ii) facilitar a implementação de programas conjuntos que aumentem a produtividade, tais como just in time e gestão on line dos estoques dos clientes pelos fornecedores; (iii) aumentar a velocidade de desenvolvimento e lançamento de novos produtos por meio de iniciativas de colaboração on line com parceiros externos; (iv) comunicar mudanças nos produtos, promoções e níveis de estoque instantaneamente para os distribuidores, de modo a melhorar a competitividade da rede estratégica; (v) desenvolver novos canais de venda em nível global para aumentar as receitas; (vi) aumentar a satisfação do consumidor pela oferta de serviços on line, como localização de carga ao longo de toda a cadeia de suprimentos; (vii) automatizar as iniciativas com os fornecedores durante a gestão da carga do cliente.

Percebe-se a atuação efetiva da TI na SCM em processos como níveis de estoque, tempo de ciclo, processos de negócios e serviços ao consumidor, fato corroborado por Turban, McLean e Wetherbe (2004, p. 215).

O reconhecimento dos benefícios da TI na SCM neste estudo será norteado pelos itens: (i) satisfação do cliente; (ii) aumento da precisão do prazo de entrega; (iii) aumento do nível de comunicação e integração; (iv) eficiência no planejamento e desenvolvimento das atividades; (v) eliminação de processos manuais; (vi) inovação em práticas e processos; (vii) redução de custos operacionais; (viii) redução do tempo de ciclos de processos; (ix) redução de erros e devoluções; e (x) aumento da flexibilidade.
Compartilhamento da informação na gestão da cadeia de suprimentos

Há níveis distintos de compartilhamento de informações na cadeia de suprimentos. O primeiro nível vincula-se ao processo tradicional, onde o fabricante e o varejista são de organizações diferentes e atuam de forma descentralizada. No nível subsequente, o fabricante e o varejista mantêm suas políticas de inventário sob controle coordenado, permitindo o acesso a determinadas informações dos clientes, como demanda e as informações sobre pedidos. No terceiro nível, o fabricante e o varejista cooperam entre si, por exemplo, via EDI. O primeiro estabelece a sua política de inventário e o segundo disponibiliza informações diretamente, o que favorece a ambos contribuir na decisão de reabastecimento (CHENG; WU, 2005).

O fluxo de informações presente na GCS contribui para a redução da incerteza na previsão das ocorrências. Sem esse aviso antecipado, a saída antes encontrada pelas companhias contra a variação no suprimento e na demanda era a manutenção de estoque no nível indicado para atender à demanda e ao suprimento. Dessa forma, o estoque passa a ser substituído pela informação, alternativa menos onerosa (TAYLOR, 2005).

Convém enfatizar também a necessidade de entender qual a informação que deve ser compartilhada, na tentativa de perceber a importância que ela desempenha na GCS. São listadas abaixo aquelas selecionadas para a pesquisa de campo: (i) custos; (ii) envio de mercadorias; (iii) estoque; (iv) faturamento; (v) indicadores de produtividade; (vi) indicadores de qualidade; (vii) informações estratégicas; (viii) opiniões de clientes; (ix) pesquisa e desenvolvimento; (x) pedidos; (xi) preços; e (xii) programação de frotas e roteiros.

Acrescentou-se ainda que serão conhecidas as frequências de compartilhamento, sendo ressaltadas as categorias "frequentemente", "raramente" e "nunca", para cada tipo de informação exposta acima.

Barreiras ao uso da tecnologia da informação na gestão da cadeia de suprimentos

Algumas dificuldades são conhecidas na fase de implementação da GCS, já que, 
na maioria dos casos são necessários altos investimentos em tecnologia da informação, tendo em vista a existência de sistemas independentes, que não conversam entre si e que são utilizados nas atividades rotineiras de operação e de controle (NOVAES, 2001).

Outros obstáculos podem surgir no momento da utilização, como a resistência ao uso e, ainda, as fragilidades em relação à segurança e garantia da integridade dos dados presentes no software.

No que se refere à gestão da cadeia de suprimentos, a situação não é diferente. Para orientar a pesquisa de campo, foram selecionadas as barreiras listadas a seguir, que podem limitar uso da TI na GCS: (i) conflitos internos; (ii) cultura; (iii) custo; (iv) disponibilidade; (v) privacidade e segurança; e (vi) falta de necessidade.

\section{Aspectos metodológicos}

A pesquisa dividiu-se em três partes e cada uma delas subdividiu-se em fases. A primeira parte foi teórica, momento em que o tema foi definido e delimitado, após revisão de literatura. Esta fase da pesquisa forneceu ainda subsídios para a estruturação do instrumento utilizado na fase seguinte, quando foi construído o questionário para pesquisa de campo. Em seguida, na segunda parte, foi realizada a pesquisa de campo, com o envio do instrumento de coleta de dados via e-mail e visita a algumas empresas que não responderam por meio eletrônico. Por fim, procedeu-se à análise dos dados coletados.

Para a construção desse instrumento de coleta de dados foram seguidos os seguintes passos: listagem das variáveis que se pretende medir ou descrever; revisão do significado de cada variável e, finalmente, revisão de como cada variável será medida ou descrita.

O questionário constituiu-se de perguntas fechadas e abertas. Os respondentes indicaram preponderantemente o tipo de tecnologia da informação utilizado, a frequência de uso, os benefícios percebidos com essa utilização e a forma de compartilhamento da informação.

As perguntas abertas relacionaram-se às razões da não utilização da TI na GCS, assim como ao investimento que poderia ser feito pela organização, ou seja, o que a empre- sa pretenderia implantar em termos de TI nos próximos anos.

Os dados foram coletados nos meses de outubro e novembro de 2009, por meio de questionário elaborado no site survey monkey.

A investigação foi realizada junto aos fornecedores cadastrados no Programa de Desenvolvimento de Fornecedores do Maranhão que atuam na cidade de São Luís - 350 empresas. Estas empresas forma conhecidas através da Secretaria de Indústria e Comércio, órgão vinculado ao Governo do Estado do Maranhão, mantenedor do Programa de Desenvolvimento de Fornecedores do Maranhão, que pretende gerar novas oportunidades de negócios e contribuir para a melhoria da distribuição de renda no Estado (MARANHÃO, 2009).

O questionário foi distribuído para as 350 empresas, das quais 50 efetivamente responderam, representando uma amostra de $13 \%$.

Os sujeitos da pesquisa foram os diretores e gestores que atuam na área de TI das empresas fornecedoras cadastradas no Programa de Desenvolvimento de Fornecedores do Maranhão. Para a escolha dos sujeitos, observou-se ser fundamental que as pessoas selecionadas conheçam a estrutura de TI de que a empresa dispõe, assim como os planos de investimento, contemplando as melhorias em tal estrutura, a preferência era que o responsável pela área de TI respondesse à pesquisa, mas caso não existisse uma área de TI formalizada, o gestor do negócio é quem deveria responder.

Dos participantes pesquisados, $56 \%$ compõem o ramo de serviços e indústria, seguido pelo comércio, com $26 \%$. Na sequência, tem-se $10 \%$ para o ramo da construção civil, além de engenharia e projetos e fabricação e montagem, com $6 \%$ e $2 \%$, respectivamente.

O ramo de atuação que apresenta a maior faixa de faturamento, bem como o maior número de empregados, é o de serviço e indústria, seguido pelo ramo da construção civil. Já os de comércio e engenharia e projetos foram enquadrados com as menores faixas de faturamento e em número de funcionários.

Dentre as empresas pesquisadas, 37\% não responderam à pergunta sobre o faturamento anual. Já $14 \%$ preferiram não responder também à questão relacionada ao número 
de empregados que compõem à organização. Acrescenta-se ainda que o tempo médio de atuação das empresas respondentes no mercado é de 16 anos, sendo a que a mais antiga tem 59 anos e a mais nova apenas um.

No que se refere às pessoas que responderam ao questionário, houve concentração maior em outros cargos de gestão (47\%), que incluem gerentes de negócios, de suprimentos, de controladoria, coordenador administrativo, entre outros. Os cargos de alta gestão foram responsáveis por $28 \%$ da participação, enquanto os da área de TI representam 15\% da amostra, na terceira posição. Cargos na área de qualidade totalizaram $11 \%$ da amostra. É possível supor que as empresas, na sua maioria, podem não ter ocupantes de cargos na área de TI, assim como podem não dispor, em suas estruturas, de uma área formalmente constituída voltada à Tecnologia da Informação. Esta caracterização dos respondentes deve ser levada em conta na interpretação dos resultados da pesquisa, pois não se sabe o grau de conhecimento que eles têm sobre TI.

Os dados foram tratados através da estatística descritiva, com base nas informações disponibilizadas pelos participantes da amostra sobre à utilização da TI na GCS.

No que se refere à representação gráfica dos dados coletados, a fim de facilitar a interpretação dos resultados, usaram-se gráficos em colunas e em setores que contribuíram para a exposição dos resultados.

\section{Análise de dados}

Os gráficos 1, 2 e 3 apresentam a utilização de TI pela empresas pesquisadas. Tal divisão foi feita na tentativa de facilitar a leitura e visualização dos resultados.

O primeiro deles, o gráfico 1 , trata dos sistemas de identificação por rádio frequência (RFID), sistema de execução de manufatura (MES), sistema de gerenciamento de transporte (TMS) e rastreamento de frota. Nota-se uma expressiva participação das tecnologias consideradas pelos respondentes como não adequadas ao seu ramo de atuação, categorizadas como não se aplica, sendo elas: RFID - 54\%; MES - 46\%; TMS e rastreamento de frotas - ambos com $45 \%$.

Pode-se inferir que este resultado indica uma incidência grande de não utilização das tecnologias, entretanto não se pode afirmar que tais tecnologias não se aplicam ao negócio da empresa. Este aspecto pode estar vinculado à avaliação indevida que as empresas podem fazer de que atuam em um ramo que não necessita destes recursos de TI, uma vez que estas são as tecnologias mais avançadas.

Entretanto, destacam-se os percentuais obtidos na categoria de uso frequente, $23 \%$ e $26 \%$, para o TMS e o rastreamento de frotas, respectivamente. Estas tecnologias têm assim uma relativa aceitação entre os fornecedores locais.

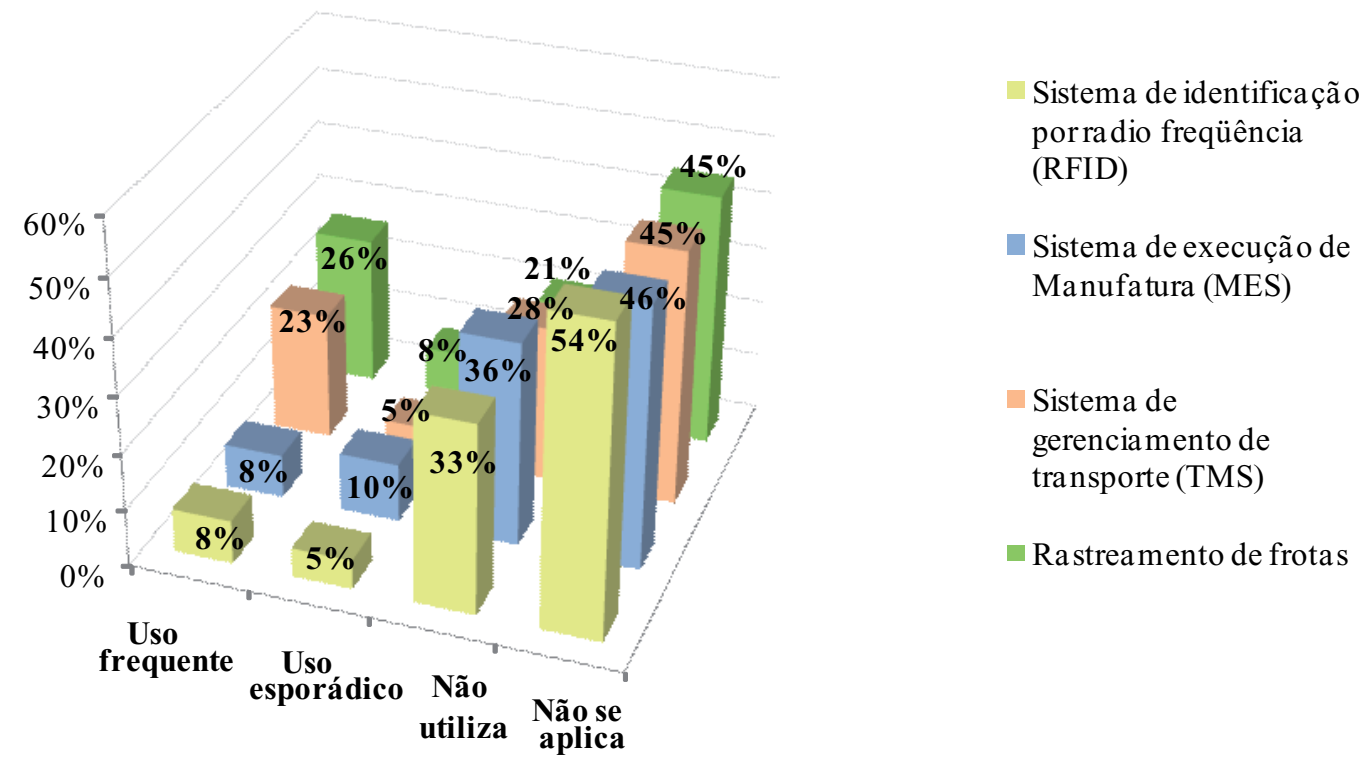

Gráfico 1 - Tipo de tecnologia utilizada e frequência de utilização 
O uso dos sistemas de gestão de armazém (WMS), de código de barras, de desenho assistido por computador (CAD) e de planejamento da cadeia de suprimentos (SCP) é retratado no gráfico 2. Dos percentuais obtidos, merecem ser destacados os relacionados ao uso frequente: $31 \%$ para o WMS e $28 \%$ para o SCP. Novamente, a categoria não utiliza tem uma considerável expressão: $38 \%, 33 \%$ e $28 \%$, para o SCP, o código de barras e o WMS, respectivamente.

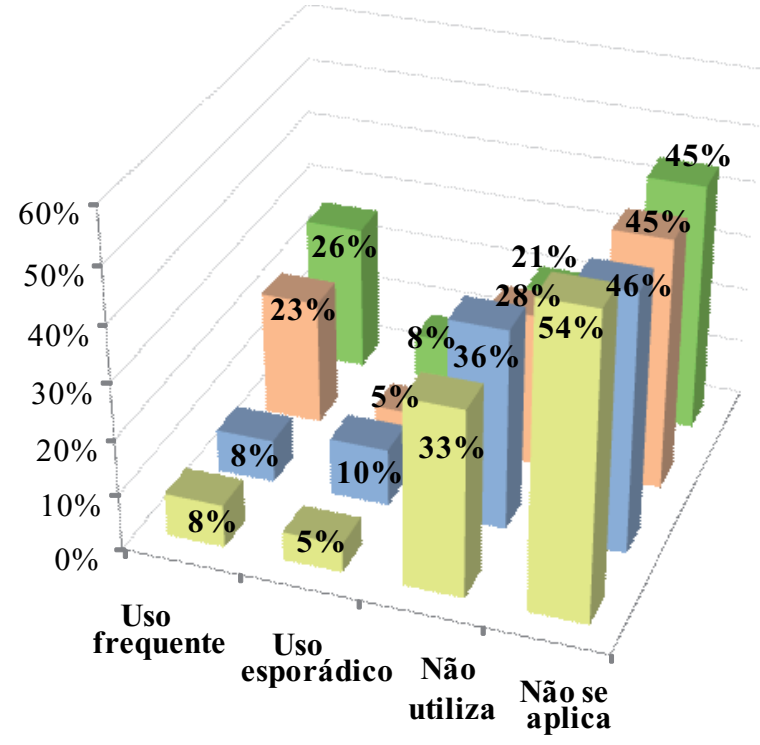

Sistema de identifica ção porradio freqüência (RFID)

- Sistema de execução de Manufatura (MES)

Sistema de gerenciamento de transporte (TMS)

Rastreamento de frotas

Gráfico 2 - Tipo de tecnologia utilizada e frequência de utilização

O gráfico 3 apresenta as tecnologias de uso frequente no mercado local. São elas: intranet/extranet - $80 \%$; sistema integrado de gestão (ERP) - 66\%; intercâmbio eletrônico de dados (EDI) - 59\% e sistema de gestão de relacionamento com cliente (CRM) - 40\%. É importante enfatizar que neste gráfico são apresentadas ferramentas utilizadas usualmente e, também, menos específicas.

Os reduzidos percentuais obtidos na categoria "não se aplica", de 5\% a 13\%, indicam que apesar de não utilizarem as tecnologias indicadas, de $5 \%$ a $38 \%$, de acordo com a tecnologia, as empresas reconhecem que elas podem se aplicar ao negócio.

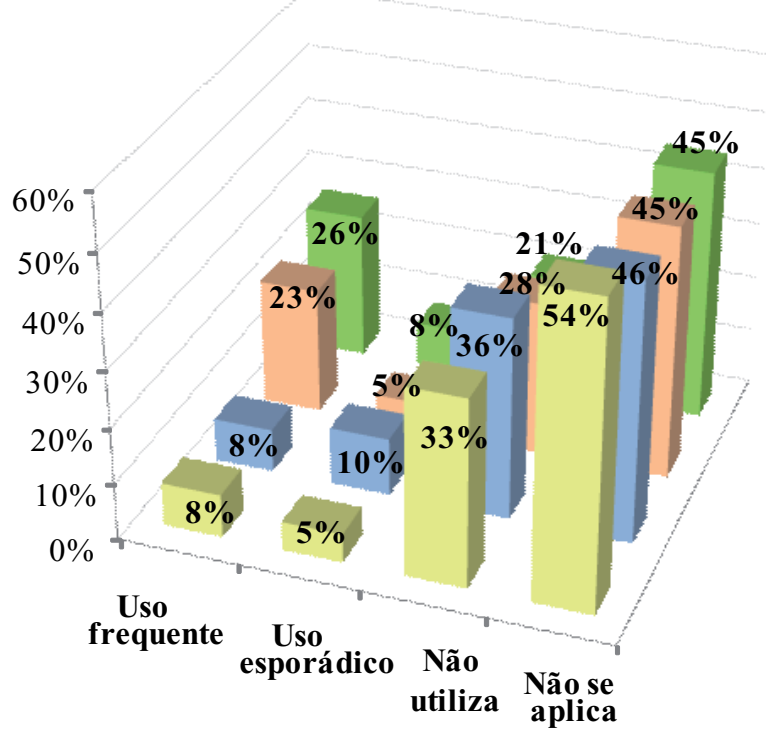

Sistema de identifica çãı
por radio freqüência
(RFID)
Sistema de execução de
Manufa tura (MES)
Sistema de
gerenciamento de
transporte (TMS)
Rastreamento de frotas

Gráfico 3 - Tipo de tecnologia utilizada e frequência de utilização 
Dentre as razões para a não utilização da TI, os dados expostos no gráfico 4 indicaram que para $69 \%$ as ferramentas não se aplicam ao ramo de atuação da empresa, ou seja, esta parcela acredita que o tipo de TI não é relevante para o seu tipo de negócio. Há, ainda, aqueles que, apesar de não utilizá-las, justificaram que pretendem implantar tais ferramentas na busca de melhorias, principalmente na gestão, representando apenas 31\% da amostra pesquisada.

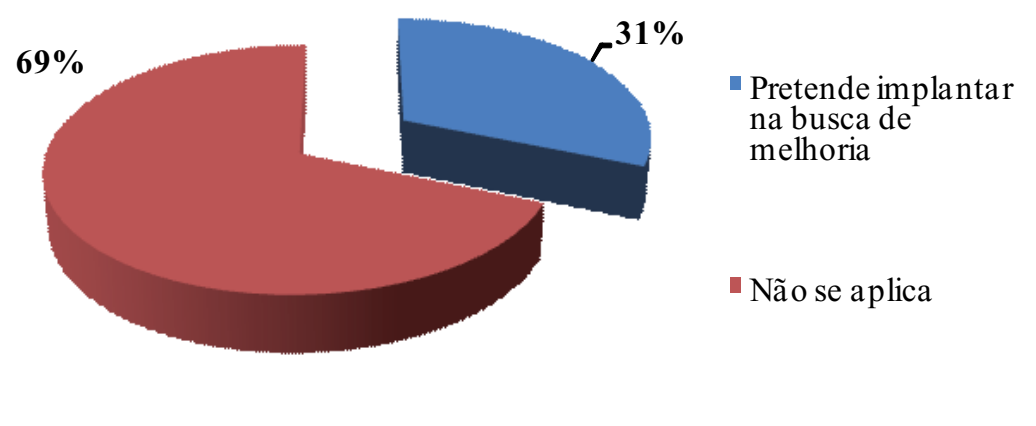

Gráfico 4 - Razões para não utilizar a tecnologia da informação

O gráfico 5 descreve os benefícios da utilização da TI apontados pelos respondentes. Foi solicitado que eles distribuíssem cem pontos proporcionalmente entre esses benefícios. Como resultado, tem-se em primeiro lugar o benefício "satisfação do cliente", com $17 \%$ da pontuação total; em seguida, "aumento do nível de comunicação e integração", com 13\%; na sequência, têm-se a "eficiência no planejamento e desenvolvimento das atividades", com $12 \%$ e em quarto lugar, a "redução dos custos operacionais" e "eliminação de processos manuais", ambos com $11 \%$.

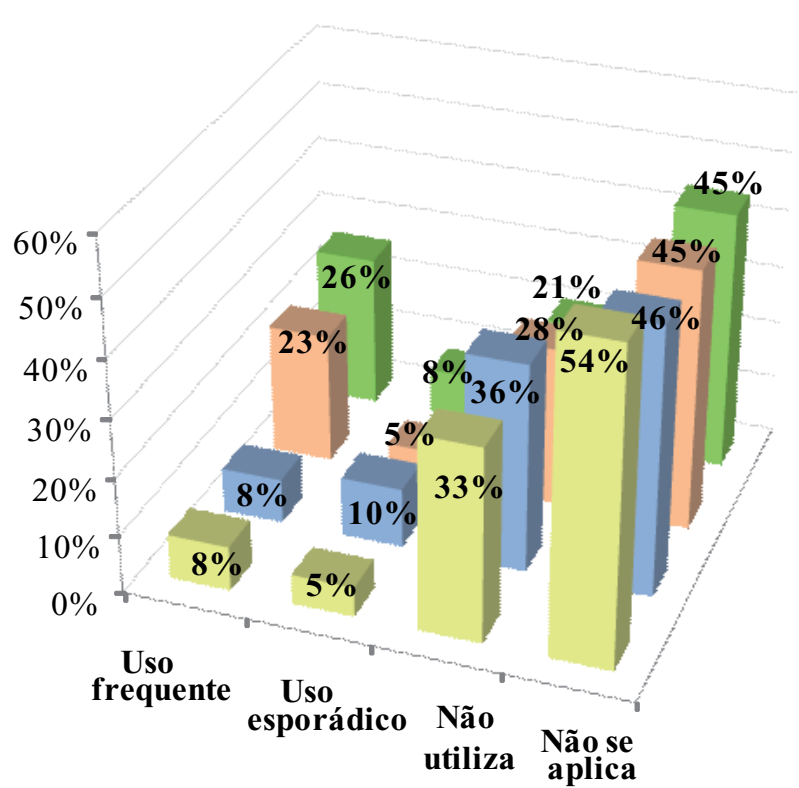

Sistema de identifica ção porradio freqüência (RFID)

- Sistema de execução de Manufatura (MES)

Sistema de
gerenciamento de
transporte (TMS)
Rastreamento de frotas

Sistema de gerenciamento de

Rastreamento de frotas

Gráfico 5 - Benefícios da utilização da tecnologia da informação 
Buscou-se também identificar quais informações são compartilhadas, a frequência de compartilhamento e com quem ela é compartilhada; se internamente; se com clientes ou com fornecedores. O gráfico 6 trata das informações que são compartilhadas nas categorias frequentemente, raramente e nunca. Dados sobre custos são compartilhados frequentemente (77\%) e predominantemente no ambiente interno (93\%). Ao que parece não há compartilhamento de informações relacionadas a custo entre as empresas pesquisadas e seus clientes e fornecedores. Tal compartilhamento com preponderância no âmbito interno restringe a possibilidade de obtenção de melhores resultados organizacionais. Percebe-se oportunidade de melhoria especialmente no que se refere à interação com fornecedores.

Em se tratando de informações sobre pedidos, o gráfico 6 retrata também o percentual de $77 \%$ de compartilhamento na categoria frequentemente, e mais uma vez o ambiente interno é onde se tem mais incidência de comunicação - 54\%. Entretanto, percebe-se certo avanço na comunicação existente entre empresa e fornecedor - $29 \%$ e entre empresa e clientes $-18 \%$. Tais dados sugerem oportunidade de melhoria na comunicação com fornecedores e principalmente com clientes, ambos ainda com comunicação incipiente e não efetiva, refletindo no atendimento ao consumidor.

Os preços também são retratados na categoria frequentemente com $77 \%$. O resultado da comunicação sobre preços indica, tal como a maioria já apresentada, alta frequência e no ambiente interno - $64 \%$, sendo preteridos os clientes e fornecedores, ambos com $18 \%$, que não têm acesso a tais informações. Isso dificulta a existência efetiva da parceria, no real sentido do termo.

Já os resultados sobre indicadores de qualidade indicam que $73 \%$ compartilham frequentemente, mas somente no ambiente interno - $52 \%$, tendo em vista que a comunicação com cliente dá-se em $44 \%$ e com fornecedores somente em $4 \%$ do universo pesquisado. Tal aspecto relacionado à qualidade do produto ou do processo teve um cenário mais favorável quando comparado aos indicadores de produtividade.

Quanto ao faturamento, notou-se uma considerável comunicação em termos de frequência - 70\% e ambiente interno - 85\%. Já a divulgação entre empresas e seus fornecedores $(4 \%)$ e clientes $(12 \%)$, pode ser considerada tímida e insuficiente, para a gestão da cadeia de suprimentos integrada.

As informações relacionadas ao estoque são compartilhadas frequentemente - $68 \%$ e internamente $-71 \%$, entretanto quando se fala em comunicação com clientes - $7 \%$ e com fornecedores - $21 \%$, os percentuais apresentam expressiva redução. Nesse caso, novamente a incidência maior no ambiente interno não permite que a companhia obtenha resultados significativos na gestão do estoque, com a interação entre empresa e fornecedor, sabendo que a comunicação efetiva com os fornecedores pode contribuir para reduzir níveis de estoques e, consequentemente, aumentar o lucro.

Em todos os indicadores comentados é visualizada maior incidência na categoria frequente e no ambiente interno, o que sinaliza oportunidade de melhoria para o compartilhamento com fornecedores e também com clientes. 

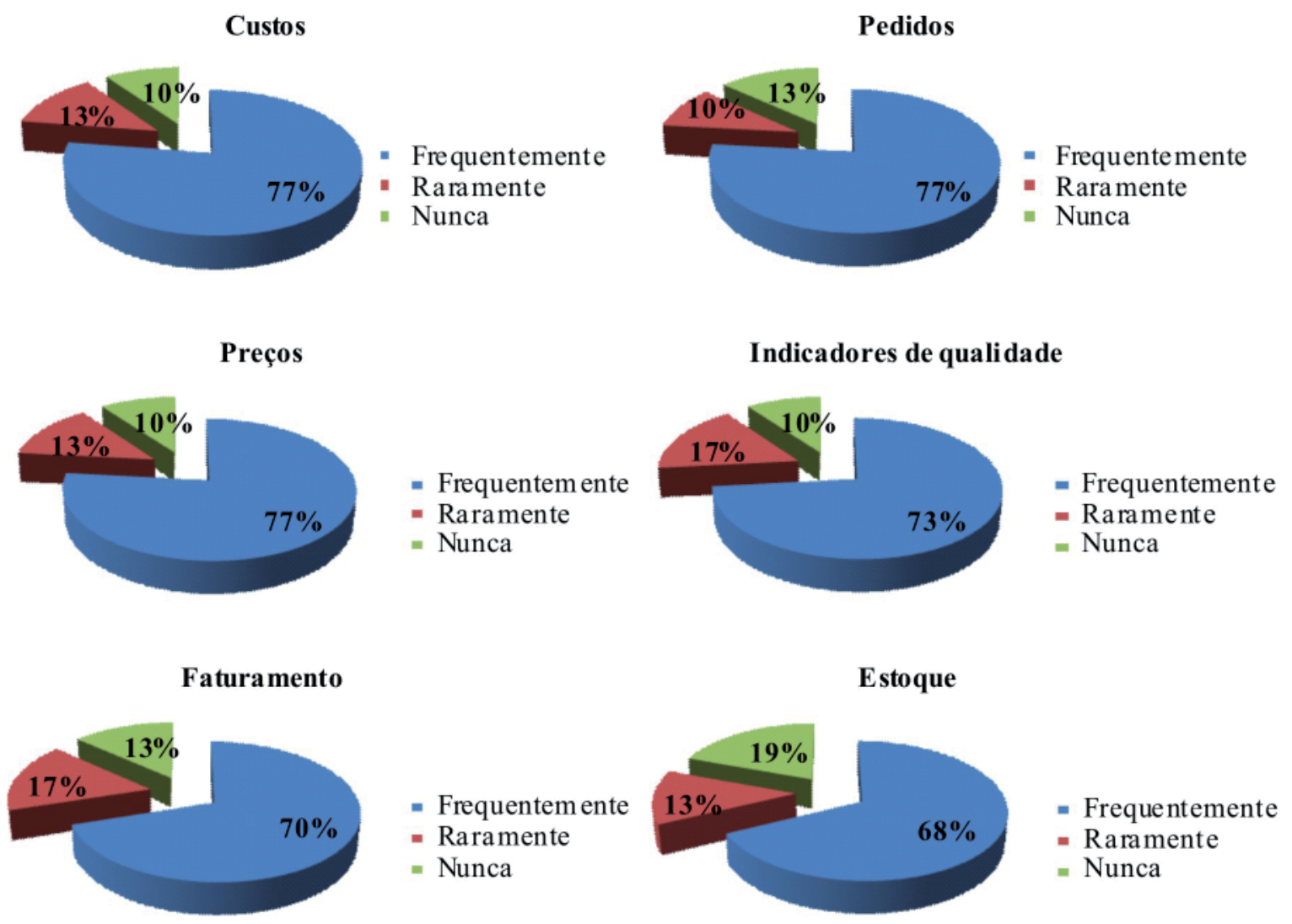

Gráfico 6 - Informações compartilhadas com frequência

O gráfico 7 apresenta as informações com percentuais de compartilhamento mais expressivos na categoria raramente, das quais destacam-se as informações estratégicas, os Indicadores de produtividade, as opiniões de clientes e as de envio de mercadorias, que variam de $57 \%$ a $40 \%$.

O resultado do compartilhamento das informações estratégicas indica que raramente as empresas divulgam suas estratégias $(40 \%)$ e, quando o fazem, priorizam a comunicação no âmbito interno - $82 \%$, sendo preterido o público externo, clientes com $11 \%$ e fornecedores, $7 \%$.

Os dados da troca de informações relativas aos indicadores de produtividade, que são importantes para o monitoramento do desempenho, apresentaram resultado mediano na categoria raramente (33\%) e com certa elevação para o ambiente interno - $62 \%$, tendo redução ainda maior no ambiente externo, com clientes $23 \%$ e fornecedores, $15 \%$.

Em se tratando das opiniões de clientes, úteis para realimentar o processo de produção de bens e serviços, também apresentaram um cenário de pouca comunicação, por exemplo, no ambiente interno obteve-se $74 \%$.

No que se refere à troca de informações sobre o envio de mercadorias, obteve-se um compartilhamento frequente e internamente, em torno de $50 \%$. 
Informações estratégic as

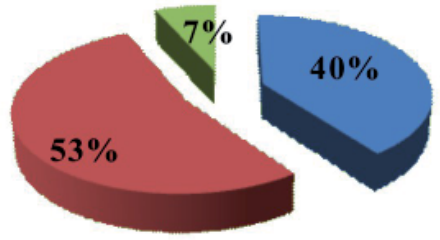

Opiniões de clientes

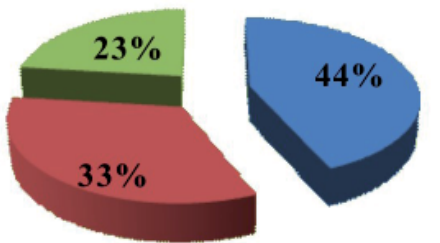

- Frequentemente

- Ra ramente

- Nunca
Indicador es de produtividade

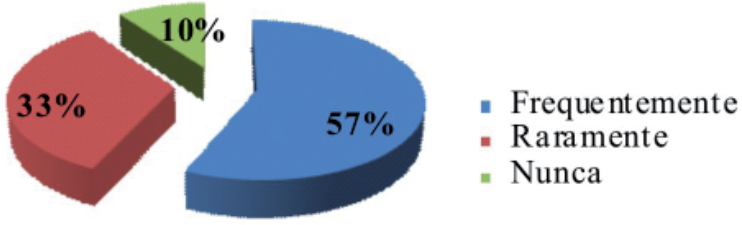

Envio de mercadorias

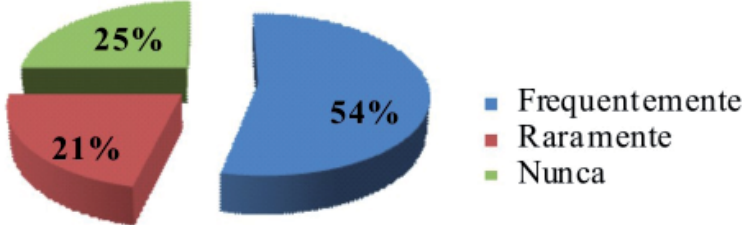

Gráfico 7 - Informações compartilhadas raramente

O gráfico 8 apresenta as informações que alcançaram maiores percentuais na categoria nunca. Destacam-se aquelas vinculadas à programação de frotas e roteiros e pesquisa e desenvolvimento (P\&D), atividades específicas, com pouca atuação no mercado local.

Dados relativos à programação de frotas e roteiros indicaram que há interação na categoria frequentemente em $35 \%$ do universo pesquisado e internamente teve-se $57 \%$.

A interação com fornecedores obteve $24 \%$ de participação, apesar de ter aumentado em relação a custos, ainda merece atenção por parte das organizações. Já a comunicação com o cliente, $19 \%$ apresenta margem para crescimento considerável.

O compartilhamento de informações sobre pesquisa e desenvolvimento é pouco frequente $-41 \%$, e concentrada no limite de atuação da empresa, - 65\%, na medida em que apresenta pouca interação com clientes e fornecedores, ambos com $17 \%$, participantes ativos do processo.

\section{Programação de frotas e roteir os}
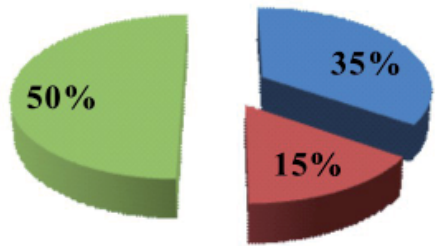

- Frequentemente

- Raramente

- Nunca

Gráfico 8 - Informações nunca compartilhadas

O gráfico 9 retrata as informações que são compartilhadas internamente, custos, faturamento, informações estratégicas, opiniões de clientes e estoque surgem como os mais lembrados nesta categoria. Os números revelam que ainda há uma lacuna no compartilhamento das informações com fornecedores. 


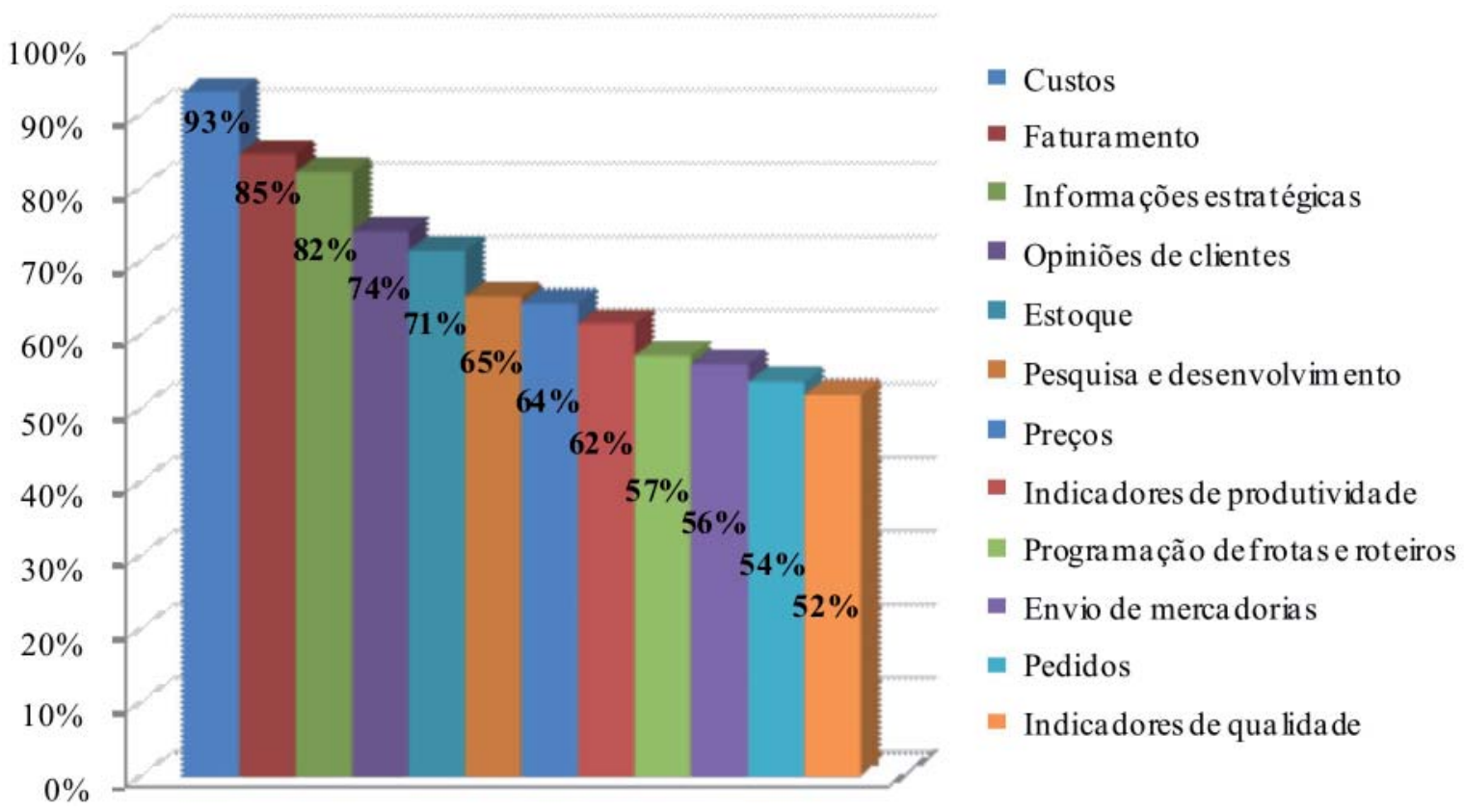

Gráfico 9 - Informações compartilhadas internamente

Foi ponto da investigação também a identificação relativa aos recursos que as empresas pretendem implantar na gestão da cadeia de suprimentos nos próximos dois anos. Esses resultados são apresentados no gráfico 10 . Nesse aspecto, $58 \%$ dos respondentes afirmaram que planejam implantar recursos que favoreçam a gestão, como sistema de controle, gestão contábil e gestão de recursos humanos. A internet e extranet aparecem com $16 \%$, na sequência, demonstrando a preocupação dos empresários em obter este recurso e, assim, facilitar sua comunicação, tanto interna quanto externa.

Sistemas de gestão, como ERP e CRM, apesar de influenciarem consideravelmente a gestão, foram separados, considerando o volume de investimentos que estes sistemas atraem na atualidade, e são citados com $10 \%$ e $8 \%$ de participação dos respondentes. Retomando os resultados de utilização do sistema integrado de gestão (ERP), com $66 \%$, e do sistema de gestão de relacionamento com cliente (CRM), com 40\%, não é correto afirmar que a perspectiva de investir nessas tecnologias é pequena.

Por fim, foram lembrados com $6 \%$ e $2 \%$, respectivamente, os recursos de hardware e código de barras, favorecendo a estrutura da gestão da cadeia de suprimentos.

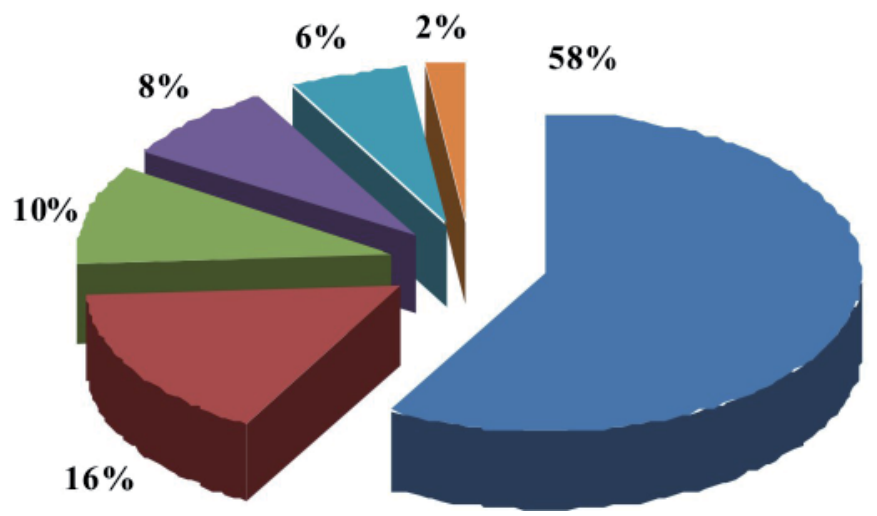

$$
\begin{aligned}
& =\text { Gestão } \\
& =\text { Internet/Intranet } \\
& =\text { ERP } \\
& =\text { CRM } \\
& =\text { Hardware } \\
& =\text { Código de barras }
\end{aligned}
$$

Gráfico 10: Recursos a implantar 
Os fatores inibidores de uso da TI, também chamados de barreiras, são apresentados no gráfico 11, quais sejam: custo - $34 \%$; cultura - $23 \%$; conflitos internos - $14 \%$; disponibilidade $-13 \%$; privacidade e segurança $-10 \%$ e falta de necessidade $-7 \%$.
Adicionalmente, é relevante destacar que pode existir uma parcela considerável da amostra que desconhece as tecnologias pesquisadas, fato que se relaciona aos altos percentuais de não se aplica ou não utiliza.

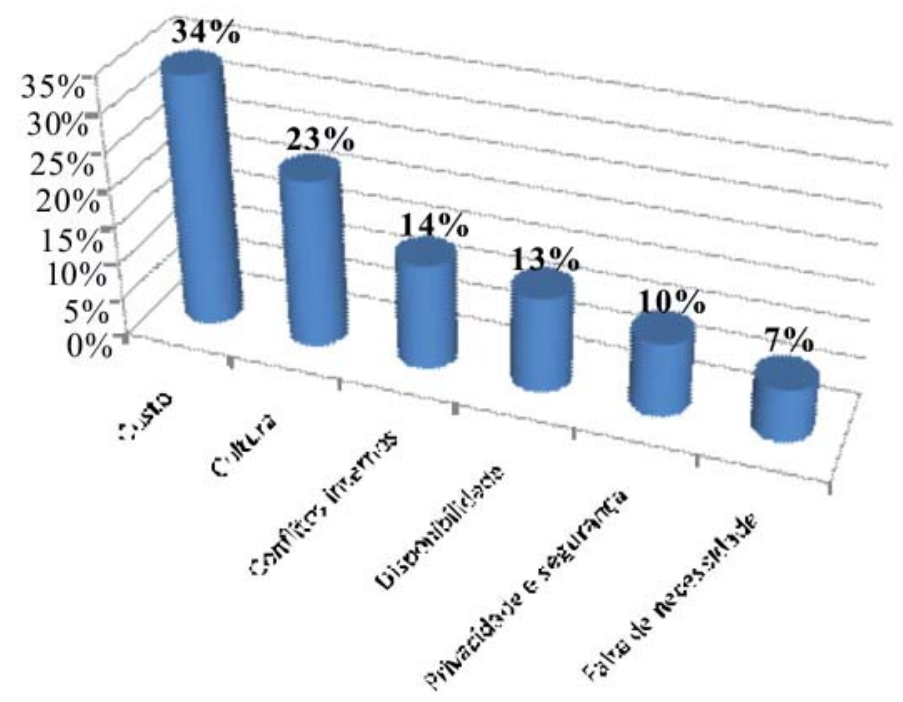

Gráfico 11 - Principais barreiras

\section{Considerações finais}

A TI na GCS tem sido utilizada como possibilidade de obtenção de vantagem competitiva na organização, principalmente através da redução de custos e melhoria no processo de comunicação entre os agentes. Sabe-se que os benefícios proporcionados pela TI na gestão das empresas tem sido frequentes.

Diante da suspeita de que o uso da TI ainda é incipiente na gestão da cadeia de suprimentos em São Luís do Maranhão, essa pesquisa consistiu num estudo panorâmico sobre o tema nesta cidade. Ela confirmou a suspeita do uso ainda incipiente dos instrumentos específicos de tecnologia da informação entre os fornecedores locais, mostrando quais tecnologias são mais ou menos utilizadas, os inibidores desta adoção, os benefícios identificados e os compartilhamentos de informação atualmente existentes.

Os resultados indicaram um uso frequente de algumas ferramentas de TI, como intranet/extranet, ERP, EDI e CRM. Porém, indicativos de uso incipiente foram encontrados, dentre os quais, ressaltam-se as tecnolo- gias como SCP, código de barras e WMS, que obtiveram elevado percentual de não utiliza e não se aplica.

Outro indicador que sinaliza a necessidade de dar mais importância à TI pode ser retratado, por exemplo, pela ausência de profissionais da área na organização, já que os mesmos não foram identificados dentre os que responderam à pesquisa. Ou ainda, pela resposta que apontou o fator custo como principal barreira à implantação de solução, não sendo visualizado como investimento, com possibilidade de retorno.

Dentre os benefícios indicados pelos respondentes como consequência da utilização da TI, podem ser ressaltados os relacionados à satisfação do cliente, o aumento do nível de comunicação e integração e a eficiência no planejamento e desenvolvimento das atividades. Embora o primeiro esteja voltado para o mercado, pode-se afirmar que tal resultado representa melhorias na gestão interna, refletindo-se para o ambiente externo e contribuindo para um desempenho superior da organização.

O compartilhamento da informação é outro aspecto que desperta atenção, tendo 
em vista que mesmo internamente, apesar de ter sido onde se tem mais interação entre os agentes, comparado a clientes e fornecedores, ainda há pontos que precisam de melhoria. Tal interação pode se refletir na obtenção de alguns benefícios, como redução de custos, agilidade e aumento da capacidade de resposta às demandas do mercado.

As barreiras relacionadas à utilização da TI identificadas constituem-se principalmente aquelas vinculadas a custo e cultura, o que exige um processo de conscientização e apresentação dos reais benefícios associados ao processo de implementação e uso de tais ferramentas. No outro extremo, com percentuais menos expressivos, são citadas como barreiras a privacidade e segurança e a falta de necessidade. Este último fator foi mantido como barreira por poder traduzir o desconhecimento dos fornecedores locais respeito dos benefícios que podem ser obtidos com o uso da TI.

Acredita-se que este estudo possa ser relevante para que os gestores que atuem no mercado local conheçam o panorama de utilização da tecnologia de informação, permitindo que realizem uma avaliação da estrutura de TI e, assim, decidam sobre como direcionar investimentos na área.

Percebe-se como principal contribuição deste trabalho a visualização de um cenário de significativas oportunidades, tendo em vista a existência de limitações quanto ao uso de ferramentas da TI na GCS, que poderão contribuir para a mudança da realidade de fornecedores locais. Tal estudo pode ser útil para o Governo do Estado, à medida que permitirá trazer subsídios para o desenvolvimento de programas de formação de fornecedores adequados, no que se refere à tecnologia da informação na gestão da cadeia de suprimentos.

Dentre os estudos que podem desdobrar-se do presente estão: (i) análise mais aprofundada dos pontos críticos percebidos na pesquisa de campo; (ii) replicação da mesma pesquisa em um período futuro para obtenção de uma análise longitudinal, avaliando a evolução em termos de utilização da TI na gestão da cadeia de suprimentos pelos fornecedores locais; e (iii) aplicação da pesquisa em outras cidades do estado e em outros estados, com vistas a permitir uma análise comparativa entre regiões.

\section{Referências}

ALBERTIN, A. L.; ALBERTIN, R. M. de M. Tecnologia de informação e desempenho empresarial: as dimensões de seu uso e sua relação com os benefícios de negócios. São Paulo: Atlas, 2005.

BALLOU, R. H. Gerenciamento da cadeia de suprimentos: planejamento, organização e logística empresarial. Porto Alegre: Bookman, 2001.

BARAT, J. (Org.). Logística e transporte no processo de globalização: oportunidades para o Brasil. São Paulo: Ed. UNESP/IEEI, 2007.

BOWERSOX, D. J.; CLOSS, D.; COOPER, M. Gestão da cadeia de suprimentos e logística. Rio de Janeiro: Elsevier, 2007.

CARR, N. G. TI já não importa. Havard Business Review Brasil, maio 2003.

CHENG, T.; WU, Y. The impact of information sharing in a two-level supply chain with multiple retailers. Journal of the Operational Research Society, n. 56, p. 115965, 2005.

CORRÊA, H. L.; CORRÊA, C. A. Administração de produção e operações: manufatura e serviços: uma abordagem estratégica. 2. ed. São Paulo: Atlas, 2006.

COSTA, J. C. Gestão da informação interorganizacional na cadeia de suprimentos automotiva. 2005. Dissertação (Mestrado) - Universidade Federal do Rio Grande do Sul, Porto Alegre, 2005.

COSTA, J. C.; MAÇADA, A. C. G. Gestão da informação nos elos da cadeia de suprimentos do setor automotivo brasileiro. In: EnANPAD, 30., 2006, Salvador, 2006. v. 1. p. 1-15

CUNHA, V.; ZWICKER, R. Antecedentes do relacionamento e da performance em empresas da cadeia de suprimentos: estruturação e aplicação de modelos de equações estruturais. Revista de Administração de Empresas, v. 49, n. 2, abr./jun. 2009.

DIAS, R. M.; PITASSI, C.; JOIA, L. A. Gestão integrada da cadeia de suprimento: modelo para uma arquitetura de tecnologia da informação - o caso CVRD manganês. Rio de Janeiro: [s.n.], 2003.

FELDENS, L. F. Impacto da tecnologia da informação nas variáveis estratégicas organizacionais na gestão da cadeia de suprimentos. 2005. Dissertação (Mestrado) - Universidade Federal do Rio Grande do Sul, Porto Alegre, 2005.

FRANCISCHINI, G. P. Administração de materiais e do patrimônio. São Paulo: Pioneira Thomson Learning, 2004.

FRANCO JÚNIOR, C. F. E-business: tecnologia da informação para a gestão e negócios na internet. São Paulo: Atlas, 2001.

GILMORE, D.; TOMPKINS, J. Transport plays key role in supply strategy. ID Systems, p. 8, 2000.

GRAEML, A. R.; GRAEML, K. S.; CSILLAG, J. M. A internet e a integração da cadeia de suprimentos. In: SIMPÓSIO DE ADMINISTRAÇÃO DA PRODUÇÃO, LOGÍSTICA E OPERAÇÕES INDUSTRIAIS, FGVEAESP. Anais... São Paulo, agosto 2005.

INSTITUTO Brasileiro de Geografia e Estatística. Pesquisa Nacional por Amostra de Domicílios. 2008. Disponível 
em: <http://www.ibge.gov.br/graficos_dinamicos/ pnad2008_tic/usuarios.php>. Acesso em: 21 dez. 2009.

LAUDON, K. C.; LAUDON, J. P. Gerenciamento de sistemas de informação. Rio de Janeiro: LTC, 1999.

MAÇADA, A. C. G.; FELDENS, L. P.; SANTOS, A. M. Impacto da tecnologia da informação na gestão das cadeias de suprimentos - um estudo de casos múltiplos. Gest. Prod., São Carlos, v. 14, n. 1, p. 1-12, jan./abr. 2007.

MALHOTRA, M. K.; HEINE, M. L.; GROVER, V. Na evaluation of the relationship between management practices and computer aided design. Journal of operations management, n. 19, v. 3, p. 307-33, 2001.

MARANHÃO. Governo do Estado. Governo/index. São Luís, 2009. Disponível em: <http://www.ma.gov.br/ governo/index.php?Ids=16>. Acesso em: 26 ago. 2009.

MOTTA, P. R. Transformação organizacional: a teoria e a prática de inovar. Rio de Janeiro: Qualitymark, 2005.

NOVAES, A. G. Logística e gerenciamento da cadeia de distribuição: estratégia, operação e avaliação. Rio de Janeiro: Elsevier, 2001.

O'BRIEN, J. A. Sistemas de informação e as decisões na era da internet. São Paulo: Saraiva, 2001.
RANGANATHAN, C.; DHALIWAL, J. S.; TEO, T. S. $\mathrm{H}$. Assimilation and diffusion of web technologies in supply-chain management: an examination of key drivers and performance impacts. International Journal of Electronic Commerce, v. 9, n. 1, p. 127-61, 2004.

SANTOS, B. L.; SMITH, L. S. RFID in the Supply Chain: Panacea or Pandora's Box? Communications of the ACM, v. 51, n. 10, p. 127-31, 2008.

TAYLOR, D. A. Logística na cadeia de suprimentos: uma perspectiva gerencial. Tradução de Claudia Freire. São Paulo: Pearson Addison-Wesley, 2005.

TURBAN, E.; MCLEAN, E.; WETHERBE, J. Tecnologia da informação para gestão. Tradução de Renate Schinke. 3.ed. Porto Alegre: Bookman, 2004.

WANG, E. T. G.; WEI, H. Interorganizational governance value creation: coordinating for information visibility and flexibility in supply chains. Decision Sciences, v. 38, n. 4, p. 647-74, 2007.

WOUTERS, J. Customer service as a competitive marketing instrument: an investigation into the construction and measurement equipment supply chains. $17^{\text {th }}$ Annual IMP Conference, p. 9-11. Oslo, Norway. September, 2001. 
